\title{
DE REYES A PEONES. RESEÑA DEL LIBRO: LECHINI, G. Y MORASSO, C. (2020). AUGE Y OCASO DE LOS EMERGENTES EN EL SIGLO XXI ¿CAMBIOS SISTÉMICOS, DOMÉSTICOS O COSMÉTICOS? UNIVERSIDAD NACIONAL DE ROSARIO.
}

\section{Alonso Herrera Arrieta}

Las investigadoras Gladys Lechini y Carla Morasso de la Universidad Nacional de Rosario (UNR), fueron las encargadas de compilar el libro Auge y Ocaso de los emergentes en el siglo XXI ¿Cambios sistémicos, domésticos o cosméticos?. Esta obra articula investigaciones a profundidad relacionadas con casos específicos que causaron desgaste político en los países emergentes, al debilitar o transformar su política doméstica y exterior. Para ello, el libro recurre a términos teóricos de las Relaciones Internacionales, oscilantes entre la cooperación y el conflicto.

Entre la relevancia teórica de los casos de estudios se encuentran las dinámicas de poder como un eje articulador cíclico de auge y ocaso en el sistema internacional. Conceptos como el hard power, en el sentido tradicional de la fuerza militar; el soft power, con el fin de obtener resultados por medio de la seducción y la cooptación; el smart power como una aleación "inteligente" de los dos tipos de poder anterior; el sharp power, como un habilidad de manipulación en la capacidad de influencia de un Estado sobre otro, creando un panorama de tensión al manipularse la información; y el poder negociador, como la capacidad que posee un Estado para alcanzar resultados a su favor, -siendo característica de países menos poderosos que se han posicionado en la agenda internacional en temáticas como cambio climático, género, integración, entre otros (Lechini \& Morasso, 2020).

En el capítulo 1, Leonardo Ramos, Filipe Mendonça, Julio Buere y Javier Vadell, presentan los condicionantes domésticos de la política brasileña, resaltando una débil ruta de concordancia entre las ideas de su agenda política, durante 
los cambios o transiciones de gobiernos entre Lula da Silva, Dilma Rousseff, Michel Temer y Jair Bolsonaro. Ideas contraproducentes para el "Partido da Ordem", el Ministerio de Relaciones Exteriores de Brasil y el Gobierno central. Ideas conexas a crisis institucionales, entorpeciendo la diplomacia brasileña en dos proyectos principales que reforzaban el liderazgo regional de Brasil en la zona: la candidatura del país a la Organización para la Cooperación y el Desarrollo Económico (OCDE) y la conclusión del acuerdo Mercosur con la Unión Europea. En relación con la crisis regional sudamericana María Victoria Álvarez desarrolla en el capítulo 2 la cuestionante sobre qué ocurre con el regionalismo y los procesos de integración, específicamente cuando el liderazgo regional comienza a deteriorarse, siendo ejemplos Brasil y Venezuela con los bloques de UNASUR y ALBA, respectivamente.

En continuidad con la región sudamericana, María del Pilar Bueno en el capítulo 3 estudia el caso de las negociaciones multilaterales en acuerdos ante el cambio climático entre Brasil, Argentina y Uruguay, con su política ambiental internacional 2016-2018. La autora examina el perfil ambiental de cada uno de los actores entre 1990-2014, a la vez que les analiza como bloque regional. Un bloque producto de disparidades políticas, posiciones en cuanto a liderazgos y lucha de intereses individuales. Como epílogo para la región sudamericana, las investigaciones confirman la importancia económica que aún representa Brasil, pese a sus crisis internas, altas tasas de pobreza y vulnerabilidad. El auge de Venezuela como potencia regional a inicios del siglo XXI, con recursos provenientes de la renta petrolera y la atracción de socios centroamericanos y del Caribe, mediante un discurso ideológico de izquierda y antiestadounidense, plasmando estos ímpetu con agendas de cooperación multilateral como el ALBA y UNASUR.

Este auge se acompañó con el ocaso de las potencias, entre los cambios domésticos que destacan se encuentran: escándalos de corrupción desde el gobierno de Dilma Rousseff (2011-2016), aunado al proceso de impeachment en su contra; seguido por la asunción de Temer que generó cuestionamientos y debilitó al poder ejecutivo. El cambio ideológico abrupto de gobiernos de izquierda a extrema derecha con la figura de Jair Bolsonaro, trajo casos de nepotismo dentro del Ejecutivo, y el acercamiento con el presidente de los Estados Unidos, Donald Trump. Estos cambios incidieron en el ocaso de organismos como UNASUR. Por otra parte, Venezuela comenzó debilitarse con el cuestionamientos al rentismo petrolero -que permitió consolidar asociaciones políticas-, y luego las enfermedades que afectaron a Hugo Chávez, derivaron en una crisis de liderazgo regional. En cuanto a Argentina y Uruguay, la disparidad de perfiles en política ambiental e intereses distintos entre sus agendas, fueron la causa 
principal de que nunca existiera un consenso ni comunicación política como bloque con Brasil.

Pasando a la región africana, María Noel Dussort en el capítulo 4 demuestra la presencia de India y China en el continente africano mediante la injerencia de proyectos de cooperación y en la política doméstica de países como Sudáfrica y Angola. Para esto explora un quiebre en el paradigma de la literatura occidental en Relaciones Internacionales, la cual ha clasificado a potencias tradicionales como EE. UU., Rusia, Gran Bretaña, Alemania, España y Portugal, como actores principales y únicos en las relaciones extracontinentales con África. No reconociendo a China e India como actores que han estado presentes en la historiografía del lugar y dándoles la falsa categoría de new comers.

La presencia de India en el continente responde en su mayor parte a un tema político de prevalencia cultural. Esta política se ha caracterizado por iniciativas que vinculan a todo el continente, como: el tratamiento de la diáspora india y las luchas anticoloniales contra racismos institucionalizados. Así, Estados que han compartido nexus colonialistas con el imperio británico, como el caso de Nigeria, las relaciones han sido más amplias al tener un pasado en común (Dussort, 2020).

En cuanto a China, su interés se ha caracterizado por una agenda de cooperación económica con tácticas más agresivas desde la llegada de Deng Xiaoping. En el capítulo 5, Agustina Marchetti enfatiza las inversiones de China en Angola en el área de infraestructura, siendo ejemplo la reconstrucción del proyecto ferroviario del Caminho de ferro de Moçamedes. Angola resultó ser un atractivo para la cooperación china por sus recursos naturales, enfocándose en la producción, extracción y movilización de estos, y por otra parte Angola se presentó con necesidad de esta cooperación china por la debilidad institucional tras una guerra civil en 2002.

Marchetti (2020), describe esta relación en un plano de poder desigual e incómoda para Angola. En 2017 el país destinó el 2,86 \% de su Producto Interno Bruto a infraestructura, posicionando un sin número de empresas chinas en materia de construcciones. El incremento de la inversión extranjera directa, el crédito y las prestaciones para los países africanos, ha sido incómoda al aumentar, año a año, las cifras de la deuda. Sin embargo Estados como Angola, se muestran ante la encrucijada de aceptar esta relación desigual de poder como un mal necesario, y apuntan a reflexionar por una parte sobre la intencionalidad china en la zona, en condiciones de ganar recursos, posicionamiento geopolítico y comercial con proyectos ferroviarios que dinamizan la economía. Y por otra parte, sobre las nuevas formas de colonización que se siguen presentando el continente africano. 
En esta misma línea, Clarisa Giaccaglia y Carla Morasso, en el capítulo 6, desarrollan amenazas domésticas en Sudáfrica, resultantes en un desgaste político en el tradicional partido African National Congress (ANC) e implicaciones en su imagen a nivel internacional. El ANC se posicionó como un partido político nacionalista, que logró superar el apartheid y se presentó con un pasado heroico en los movimientos de liberación africana. Sin embargo, la crisis que describen las autoras va más allá de factores intrapartidarios, sino que atribuyen este debilitamiento a cambios sociopolíticos que modifican a un nuevo mapa de votantes, aunado al tránsito de problemáticas raciales a socioeconómicas. Estas dificultades desatan protestas sindicales y estudiantiles así como cuestionamientos de clase y de los gobiernos post-apartheid. Giaccaglia y Morasso (2020) concuerdan que la política exterior del ANC ha sido consciente en consolidar una agenda de cooperación sur-sur y democratizar la participación ciudadana; no obstante, ante las amenazas internas, la imagen sudafricana se ha visto afectada en materia de política exterior.

Por último, en esta lectura por regiones, Rubén Paredes Rodríguez, en el capítulo 7, posiciona a Turquía como un potencia re-emergente en la región de Medio Oriente. Paredes (2020) identifica ciertos privilegios turcos como: la ubicación geográfica transcontinental, un legado histórico imperial, el llamado milagro turco (el cual combinó economía de mercado, democracia e Islam), y el apoyo de Occidente gracias a esta última peculiaridad. Pese a ello, Turquía ha experimentado un auge y ocaso por condicionantes endógenas y exógenas, esto a partir de la segunda década del siglo XXI. Las críticas al gobierno del Partido de la Justicia y el Desarrollo (AKP), por la concentración de poder de Recep Tayyip Erdoğan; un sistema político tenso ante el abandono de la minoría kurda por parte del gobierno, -representada por el Partido de los Trabajadores del Kurdistán (PKK)-, además del devenir político en los sistemas ejecutivos y judiciales con la remoción de ministros, fiscales, jueces y policías a finales del 2013.

Como se expone en los casos anteriores que componen el libro, en los Estados mencionados se identificaron cambios en sus políticas domésticas, transformaciones en sus entornos socio-políticos y reformas económicas que han debilitado sus liderazgos, junto con crisis en un sistema internacional cambiante y dinámico. Esto ha generado un debate sobre las condiciones de estos actores emergentes y en ocasiones sobre su ocaso, replanteando cuestionamientos sobre ¿Por qué no se alcanza esa anhelada consolidación como potencias?, generando un crecimiento y liderazgo regional, pero no llegando a un ascenso total al decaer en sistemas cíclicos de crisis.

Este libro da un aporte significativo al repensar actual de las Relaciones Internacionales, pues estudia las relaciones de poder entorno a los intereses 
individuales de cada Estado, y su proyección en sus respectivas regiones con el fin de atraer socios y generar un enclave en sus liderazgos. Además del estudio de los emergentes desde su interior, el análisis teórico desde las teorías decoloniales son esenciales para observar el rumbo de los Estados ubicados en las periferias. El texto logra sistematizar de una manera muy detallada los cambios domésticos y en el sistema internacional, así como aquellos "cosméticos", y cómo estas transformaciones han desencadenado crisis políticas, económicas, sociales e histórico-culturales en Brasil, China, India, Sudáfrica, Turquía y Venezuela.

Sin duda alguna, los y las investigadoras como las compiladoras de la Universidad Nacional de Rosario realizaron una óptima lectura de los emergentes gracias a las investigaciones realizadas. Al identificar causas y efectos, se logra una comparativa de dinámicas regionales, con el uso de teorías, relaciones de poder e intereses nacionales. En ese sentido, la rigurosidad de los estudios de casos muestra metodologías de investigación, respaldados por herramientas científicas de las Ciencias Sociales, permitiendo no solo profesionales de este campo de estudio tener una aproximación teórica al tema, sino a un público general por su facilidad de comprensión detallada en el lenguaje, que si bien es cierto, presenta un sin número de datos, cada uno de esos datos se proponen de una manera minuciosa al detallar los entornos, las causas y consecuencias de los disímiles a la vez similares, auges y ocasos de los actores analizados.

\section{Referencias}

Lechini, G., y Morasso, C. (2020). Auge y Ocaso de los emergentes en el siglo XXI ¿Cambios sistémicos, domésticos o cosméticos? Universidad Nacional de Rosario. 
